\title{
Consumption and Growth Patterns of Flathead Catfish Derived From a Bioenergetics Model
}

\author{
Jakob C. Tetzlaff ${ }^{*}$, H. Jared Flowers ${ }^{\S}$ and William E. Pine III \\ School of Forest Resources and Conservation, University of Florida, Box 110600, Gainesville, FL 32653, USA
}

\begin{abstract}
Bioenergetics models offer a useful framework for assessing the consumptive demand on ecosystems from nonnative fish. Consumption estimates from bioenergetics models can be combined with estimates of population abundance to quantify population-level consumption. This study applies a new bioenergetics modeling framework, developed by Walters and Essington (this volume), to estimate bioenergetics parameters using field data commonly collected from population monitoring programs. We used growth increment and size-at-age data to estimate the parameters of the bioenergetics model described by Walters and Essington (this volume) for an introduced population of Pylodictis olivaris from the Neuse River, North Carolina. The model fit the observed growth data well and predictions of consumption patterns were consistent with observed feeding patterns. The estimated consumption pattern from the general bioenergetics model represents the first characterization of adult flathead catfish consumption. Through use of capture-recapture data, the Walters and Essington bioenergetics model is able to integrate consumption estimates with growth and demographic data. Although further validation of the model is necessary, the modeling framework provides a straightforward approach to assessing the consumptive demand of fish populations.
\end{abstract}

Key Words: Bioenergetics models, Food consumption rates, Nonnative fish, Pylodictis olivaris.

\section{INTRODUCTION}

Quantifying growth and consumption are important components of understanding the ecology of many fish species. These measures integrate information from a variety of environmental (e.g., temperature) and biotic (e.g., diet) sources into simple metrics. Estimates of growth and consumption are informative for fisheries managers and scientists in many research areas including characterizing the potential predatory impact of nonnative species [1, 2]. Combining information on growth and consumption with population demographics can help fishery managers quantify trophic demand of nonnative species and assess threats to native fish populations $[2,3]$.

Flathead catfish Pylodictis olivaris is a large piscivorous catfish species native to much of the interior of North America. This species has been introduced into at least 14 U.S. states and Canadian provinces, mostly along the Atlantic slope [4]. As an introduced piscivore, flathead catfish are thought to restructure native fish communities through predation. In several areas where flathead catfish have been introduced, they quickly establish themselves as an apex predator and declines in the abundance of native fish species have concurrently been observed in these locations [5]. Flathead catfish have been classified by the United States Geo-

*Address correspondence to this author at the School of Forest Resources and Conservation, University of Florida, Box 110600, Gainesville, FL 32653, USA; Tel: 352-392-1793; Fax: 352-393-3672; E-mail: jctetz@ufl.edu

§resent address: North Carolina Cooperative Fish and Wildlife Research Unit, Department of Biology, North Carolina State University, Raleigh, NC 27695

1874-401X/10 logic Survey (USGS) as the most biologically harmful of all fish introductions in North America [6].

Quantifying potential predatory impacts by an introduced species requires estimates of population abundance and consumption. Both of these parameters can be difficult to estimate $[7,8]$ and uncertainty in these estimates can propagate through the modeling framework leading to erroneous conclusions and potentially deleterious management actions [9]. Flathead catfish are a potentially difficult species to estimate consumption rates from bioenergetics models given life history characteristics including irregular activity patterns and intermittent feeding behaviors (described below). Flathead catfish activity patterns are generally characterized by extended low activity levels with limited movements punctuated by brief migrations associated with habitat shifts to wintering and spawning areas [10]. These activity patterns would likely require similar energetic expenditures - low levels of consumption followed by intensive feeding periods. Estimates of consumption from bioenergetics models can be biased when applied under conditions involving relatively high or low consumption levels [11]. In addition, bioenergetics models can be sensitive to variable daily consumption rates [12] and require accurate field estimates of diet [13]. Field estimates of consumption for flathead catfish are characterized by very high frequencies of empty stomachs and highly variable feeding intensity between individuals $[14,15]$. Given their large growth potential, likely high consumption rates $[5,16]$, limited movements during much the year $[10,17]$ and high occurrence of empty stomachs [15], consumption rates from traditional bioenergetics models are likely to be underestimated for flathead catfish.

The bioenergetics model described by Walters and Essington [18] allows for estimation of bioenergetics pa- 
rameters and consumption rates from commonly collected field measurements of growth. This model uses seasonal growth data from mark-recapture experiments to estimate temperature driven seasonal estimates of food consumption and metabolic rates [18]. One potential advantage of this modeling framework compared with more common approaches for estimating consumption rates is the practicality of attaining input data. This model uses field growth measures routinely collected as part of standard population assessments, as opposed to other models which require laborious laboratory feeding and respiration experiments to estimate bioenergetics parameters. Because this model integrates demographic, growth, and consumption estimates of fish populations from commonly collected field data, it is particularly useful for assessing the potential impacts of nonnative fish species for which data is often sparse. This paper is a case study of the bioenergetics model proposed by Walters and Essington [18] applied to a nonnative fish species. We used growth increment and size-at-age data to estimate the parameters of the bioenergetics model described by Walters and Essington [18] for flathead catfish in the Neuse River, North Carolina. Flathead catfish represent a strong test of the applicability of the Walters and Essington [18] model due to their primarily sedentary nature, sporadic feeding behavior, and high growth rates.

\section{METHODS}

\section{Data Collection}

We used age composition information for flathead catfish $(\mathrm{N}=114)$ collected from the Neuse River, North Carolina during fall 2001 and spring 2003 using boat-mounted, lowfrequency, pulsed DC electrofishing [1]. The Neuse River forms at the confluence of the Flat and Eno rivers in central North Carolina and flows east for 443 river kilometers before entering Pamlico Sound. All flathead catfish were sacrificed upon capture and returned to the laboratory where they were measured, sexed (when possible), and saggital otoliths were removed, prepared, and read [1].

Incremental growth measures were taken from a capturerecapture study on Contentnea Creek, a large tributary to the Neuse River near the location where fish were collected for age analyses. A concurrent radio-telemetry study confirmed movement of flathead catfish from Contentnea Creek to the Neuse River on a seasonal basis [19]. Flathead catfish from the capture-recapture study were collected at least monthly from May-November in 2000-2002 using the same collection methods employed to collect the age samples. For each fish collected, total length $(\mathrm{mm})$ and weight $(\mathrm{g})$ were recorded, stomach contents removed, and each fish was implanted with a passive integrated transponder (PIT) tag [10]. Temperature data was taken from a USGS automated temperature logger stationed on Contentnea Creek near Hookerton, North Carolina and used to develop a seasonal temperature model. This temperature model was used in the bioenergetics model to predict the annual temperature cycle throughout the lifetime of all fish.

\section{Bioenergetics Modeling}

The general bioenergetics model was fit to flathead catfish growth increment, length-at-age, and water temperature data using the model formulation described by Walters and Essington [18]. All input parameters for flathead catfish can be found in Table 1. The basic derivation of the bioenergetics model of Walters and Essington [18] begins with the general growth model [20]:

$\frac{d W}{d t}=H W^{d}-m W^{n}$,

where $W$ is somatic weight, $H W^{d}$ is the rate of energy assimilation, and $m W^{n}$ is the rate of energy losses. The $d$ and $n$ parameters describe the allometric scaling of anabolism and catabolism with mass. Assuming a constant relationship between length and weight over time as

$W=a L^{b}$,

where $L$ is length and $a$ and $b$ are constant, it is possible to derive an analogous relationship for the rate of change in length as

$$
\frac{d L}{d t}=\alpha L^{\delta}-\kappa L^{\eta}
$$

Constants in this relationship are related to those in (1) and (2) as

$$
\begin{aligned}
\alpha & =\frac{a^{d-1} H}{b}, \\
\kappa & =\frac{a^{n-1} m}{b}, \\
\delta & =b d-b+1, \text { and } \\
\eta & =b n-b+1 .
\end{aligned}
$$

Following Walters and Essington [18], we defined temperature-dependent multipliers of the anabolic and catabolic scaling parameters $\alpha$ and $\kappa$ of the length dynamic model as

$\frac{d L}{d t}=\alpha L^{\delta} Q_{c}^{\frac{(T-10)}{10}}-\kappa L^{\eta} Q_{m}^{\frac{(T-10)}{10}}$

The consumption and metabolism coefficients $\left(Q_{c}\right.$ and $Q_{m}$ ) of a Q10 relationship allow anabolism and catabolism to increase or decrease with temperature $(T)$.

The general bioenergetics model was fit hierarchically with the first model containing informative priors on both $n$ and $Q_{m}$ (metabolism constrained model). As noted by Walters and Essington [18], it is typically not possible to estimate both $d$ and $n$, nor $Q_{c}$ and $Q_{m}$ simultaneously. Prior limits on $n$, and $Q_{m}$ were based on findings from Essington et al. [21] and Clarke and Johnston [22]. Uniform prior distributions were used for each parameter (Table 1). The general bioenergetics model was fit a second time with relaxed priors on both metabolic parameters (full model) to compare posterior distributions of parameters and consumption estimates from the model using informative and relaxed priors. Posterior density functions were estimated using a Metropolis-Hastings Markov-chain Monte Carlo (MCMC) routine [23]. Four MCMC chains were run with different initial values for 500,000 iterations, with a burn-in of 2,000 iterations 
Table 1. Uniform Prior Distributions for Parameters Used in General Bioenergetics Model

\begin{tabular}{|c|c|c|c|c|}
\hline Parameter & Description & $\begin{array}{c}\text { Metabolism Constrained } \\
\text { Model }\end{array}$ & Full Model & Units \\
\hline$H$ & Net food consumption rate per $\mathrm{W}^{-\mathrm{d}}$ & $4.0-36.0$ & $4.0-36.0$ & $\mathrm{~g} \mathrm{~g}^{-1} \mathrm{yr}^{-1}$ \\
\hline$m$ & Standard metabolic rate per $\mathrm{W}^{-\mathrm{n}}$ & $2.4-24.0$ & $2.4-24.0$ & $\mathrm{~g} \mathrm{~g}^{-1} \mathrm{yr}^{-1}$ \\
\hline$n$ & Metabolism power parameter & $0.7-0.9$ & $0.50-1.0$ & - \\
\hline$Q_{m}$ & $\begin{array}{l}\text { Proportional increase in metabolism per } 10^{\circ} \mathrm{C} \text { temperature } \\
\text { increase }\end{array}$ & $1.8-2.2$ & $1.0-4.0$ & - \\
\hline$Q_{c}$ & $\begin{array}{l}\text { Proportional increase in feeding rate per } 10^{\circ} \mathrm{C} \text { temperature } \\
\text { increase }\end{array}$ & $1.0-6.0$ & $1.0-6.0$ & - \\
\hline$a$ & Intercept coefficient of length-weight relationship & $1.28 \mathrm{e}^{-5}$ & $1.28 \mathrm{e}^{-5}$ & $\mathrm{~g} \mathrm{~mm}^{-\mathrm{b}}$ \\
\hline
\end{tabular}

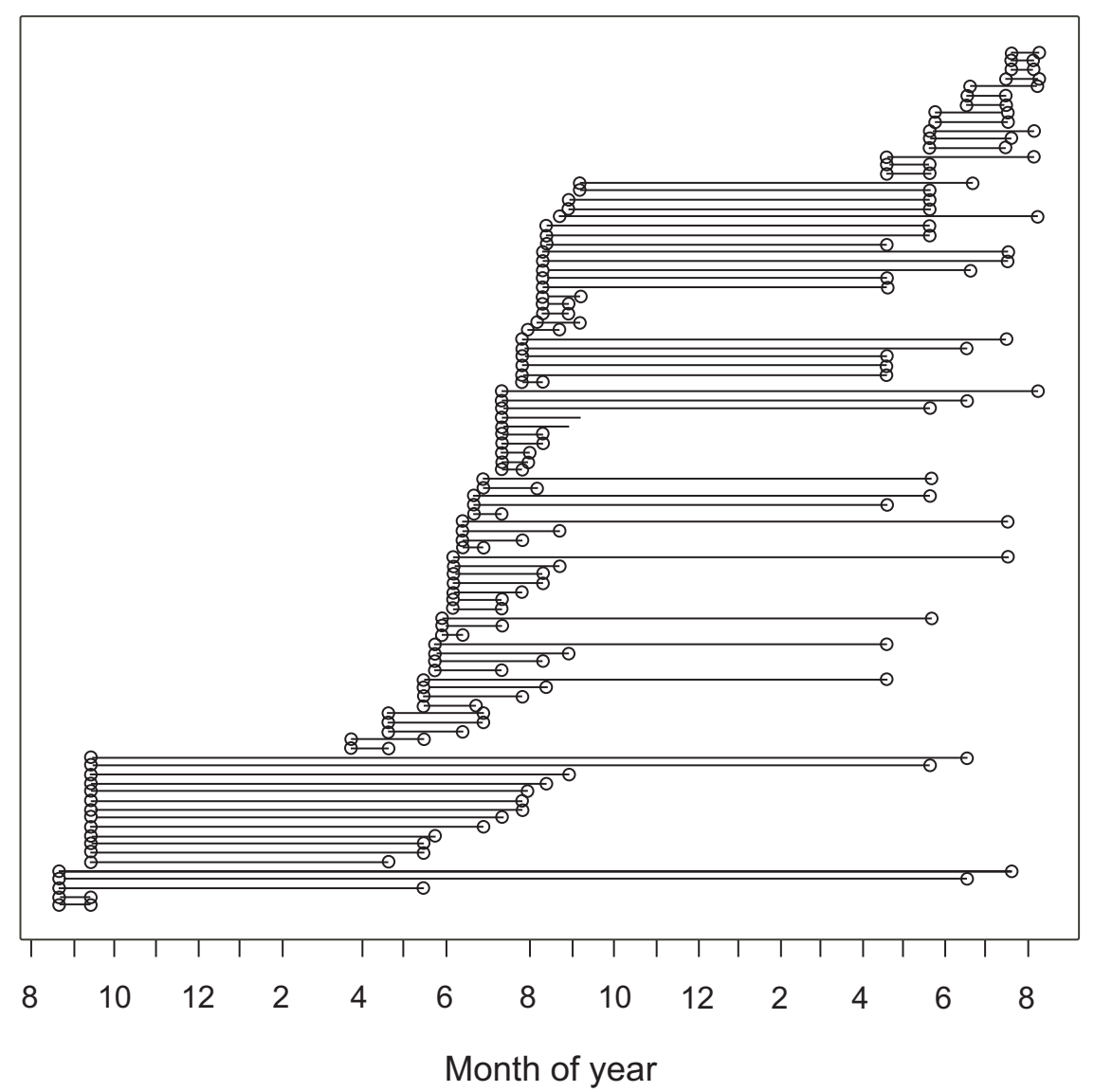

Fig. (1). Capture history of individual flathead catfish collected from the Neuse River, NC between August 2001 and August 2003.

and further thinned to leave 8,000 samples from each chain. Convergence of the MCMC routine was evaluated using the Gelman-Rubin diagnostic and inspecting trace plots for each parameter.

\section{RESULTS}

Incremental growth measures were collected on 99 flathead catfish. Recaptures of tagged fish occurred both within and between years (Fig. 1). Growth rates of fish recaptured within the same year were greater than those collected between years (Fig. 2). Average time at liberty was 43 days for fish captured and recaptured within the same year and 323 days for fish captured and recaptured between years. Within year growth increment data were collected between spring and summer months and accounted for the majority of flathead catfish growth. Between year growth increment data, from fish captured in late summer and fall and recaptured the following spring, were characterized by low growth rates. 


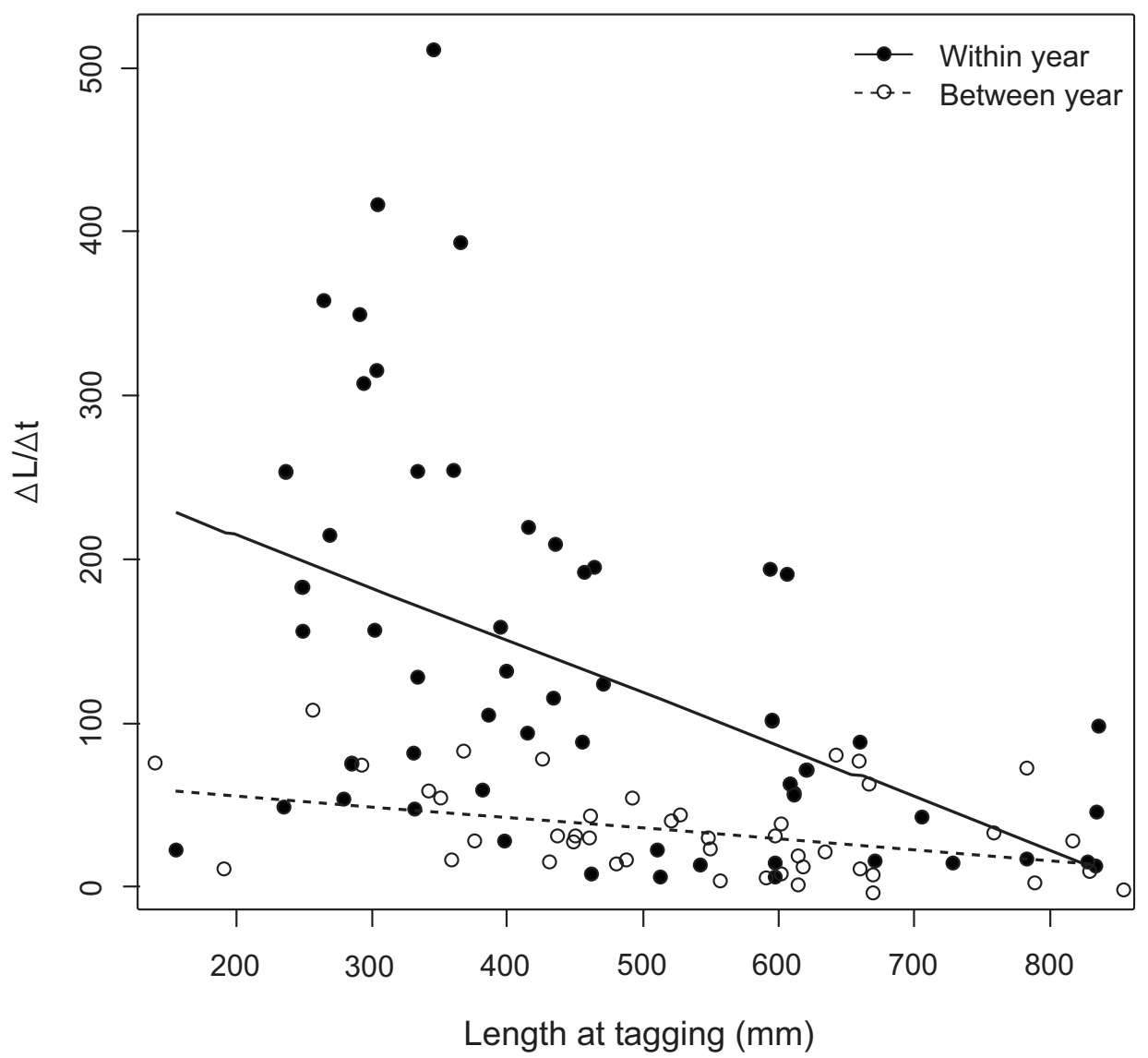

Fig. (2). Growth rate $(\Delta \mathrm{L} / \Delta \mathrm{t})$ of flathead catfish from capture-recapture data collected within the same year (over summer, closed circles) and between years (over winter, open circles) from the Neuse River, NC.

The general bioenergetics model fit observed length-atage and weight-at-age data despite high uncertainty in bioenergetics parameter estimates (Fig. 3). Gelman-Rubin diagnostics provided no evidence that the model failed to converge, with all chains having similar posterior distributions for each parameter. Trace plots for each parameter did not show any clear trends in the sampling space and all chains converged on the same region. Posterior distributions of parameter estimates were smooth and displayed a single mode; however, had high uncertainty for both fitted models (Fig. 4). Median posterior parameter estimates varied between the two fitting routines; however, 95\% posterior distributions were not different between the two routines (Table 2). Informative priors on metabolism parameters reduced uncertainty in consumption parameters $d$, and $Q_{c}$. Consumption and metabolic parameters ( $H$ and $m, d$ and $n, Q_{c}$ and $Q_{m}$ ) were highly confounded contributing to the uncertainty in parameter estimates (Fig. 5).

The general bioenergetics model predicted highly seasonal consumption and growth patterns for flathead catfish (Figs. 3 and 6). The two models predicted similar growth patterns for the first eight years of flathead catfish growth. Beyond age eight, the models diverged slightly with the metabolism constrained model predicting lower annual growth and greater weight loss over winter months (Fig. 3). The metabolism constrained model predicted slightly greater consumption than the full model over all seasons and across all ages (Fig. 6). Lifetime consumption for the metabolism constrained model was $21 \%$ greater than the full model. Peak consumption was predicted to occur during early to midsummer months with limited consumption occurring over winter months. The two models predicted that $65-75 \%$ of annual consumption occurred between May and August. The majority of annual weight gain, between $70 \%$ and $115 \%$ when reproductive losses are not included, was also predicted to occur between May and August.

\section{DISCUSSION}

The general bioenergetics model described by Walters and Essington [18] converged on a set of parameter estimates that fit the observed pattern of growth of flathead catfish. Predicted seasonality in consumption and growth is supported by observed seasonal patterns in flathead catfish activity patterns, growth condition, and feeding patterns. Convergence diagnostics on the model fitting routine displayed no evidence that the model failed to converge. However, posterior distributions demonstrated high uncertainty for some parameters. Parameter estimates and consumption predictions from the general bioenergetics model were consistent with observed flathead catfish life history patterns; however, there are no methods for statistically supporting the outputs of this model. The estimated consumption pattern from the general bioenergetics model represents the first characterization of adult flathead catfish consumption. 

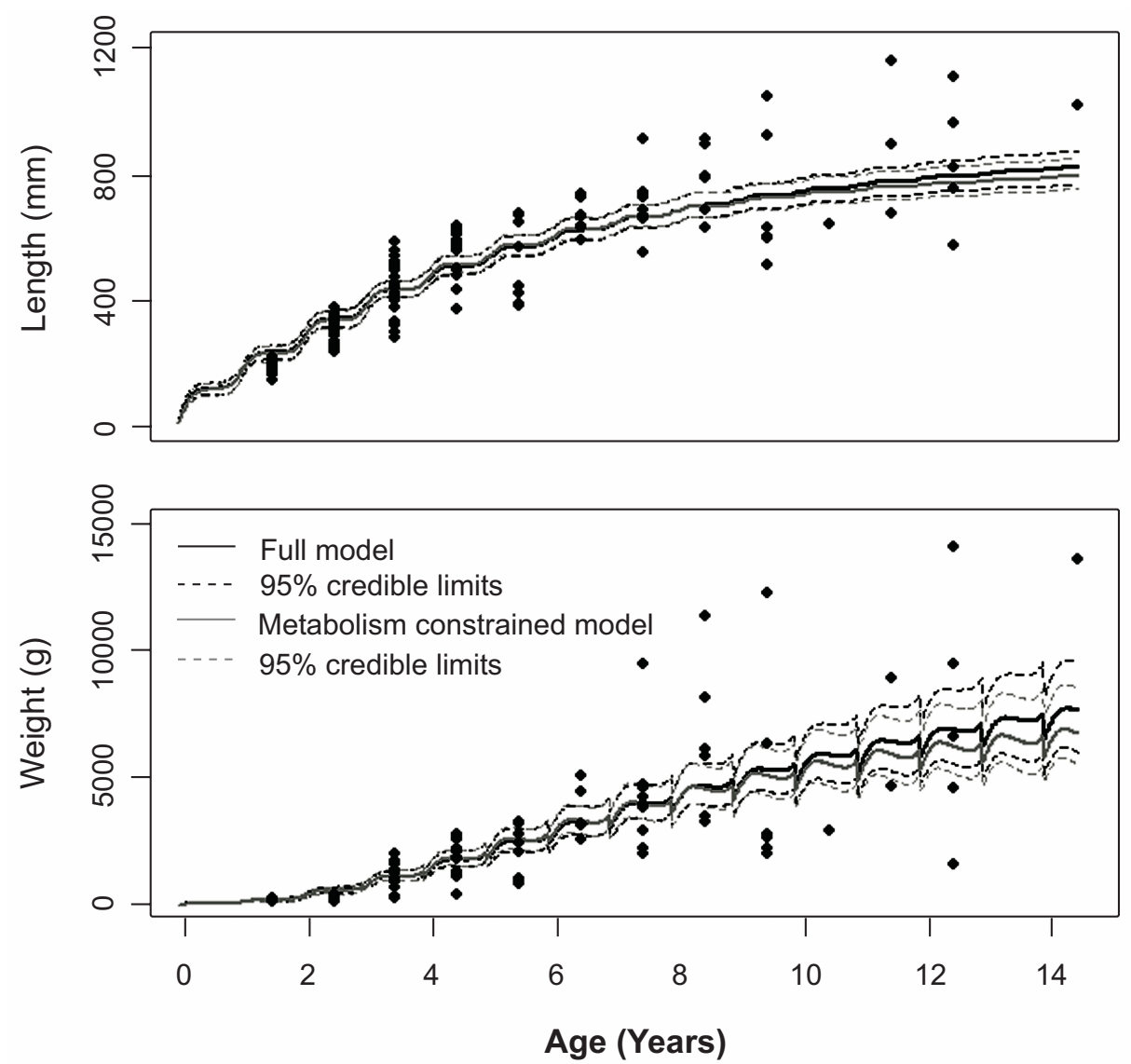

Fig. (3). Observed length-at-age (points; top panel) and weight-at-age (points; bottom panel) of flathead catfish captured in the Neuse River between fall 2001 and spring 2003 and model predicted length-at-age and weight-at-age for the full model (black line) and metabolism constrained model (grey line). Dashed lines represent Bayesian posterior $95 \%$ credible limits.

Table 2. Median and $95 \%$ Posterior Prior Distributions for Parameters Used in General Bioenergetics Model

\begin{tabular}{|c|c|c|c|c|}
\hline Parameter & Description & $\begin{array}{l}\text { Metabolism Constrained } \\
\text { Model }\end{array}$ & Full Model & Units \\
\hline$H$ & Net food consumption rate per $\mathrm{W}^{-\mathrm{d}}$ & $\begin{array}{c}13.95 \\
(5.2-29.1)\end{array}$ & $\begin{array}{c}14.28 \\
(6.1-31.1)\end{array}$ & $\mathrm{g} \mathrm{g}^{-1} \mathrm{yr}^{-1}$ \\
\hline$m$ & Standard metabolic rate per $\mathrm{W}^{-\mathrm{n}}$ & $\begin{array}{c}8.52 \\
(3.1-20.5)\end{array}$ & $\begin{array}{c}8.77 \\
(3.6-22.8)\end{array}$ & $\mathrm{g} \mathrm{g}^{-1} \mathrm{yr}^{-1}$ \\
\hline$n$ & Metabolism power parameter & $\begin{array}{c}0.72 \\
(0.70-0.82)\end{array}$ & $\begin{array}{c}0.66 \\
(0.52-.79)\end{array}$ & - \\
\hline$d$ & Food consumption power parameter & $\begin{array}{c}0.66 \\
(0.64-0.75)\end{array}$ & $\begin{array}{c}0.61 \\
(0.51-0.72)\end{array}$ & - \\
\hline$Q_{m}$ & $\begin{array}{l}\text { Proportional increase in metabolism per } 10^{\circ} \mathrm{C} \text { temperature } \\
\text { increase }\end{array}$ & $\begin{array}{c}2.04 \\
(1.81-2.18)\end{array}$ & $\begin{array}{c}1.91 \\
(1.1-3.83)\end{array}$ & - \\
\hline$Q_{c}$ & $\begin{array}{l}\text { Proportional increase in feeding rate per } 10^{\circ} \mathrm{C} \text { temperature } \\
\text { increase }\end{array}$ & $\begin{array}{c}2.36 \\
(2.09-3.49)\end{array}$ & $\begin{array}{c}2.45 \\
(1.61-4.40)\end{array}$ & - \\
\hline
\end{tabular}

Estimated consumption and growth patterns from the general bioenergetics model showed several interesting patterns. Most flathead catfish growth and consumption oc- curred during late spring and summer, primarily from MayAugust. The model estimated that $70 \%$ of the annual consumption and approximately $70-90 \%$ of the annual growth in 
H

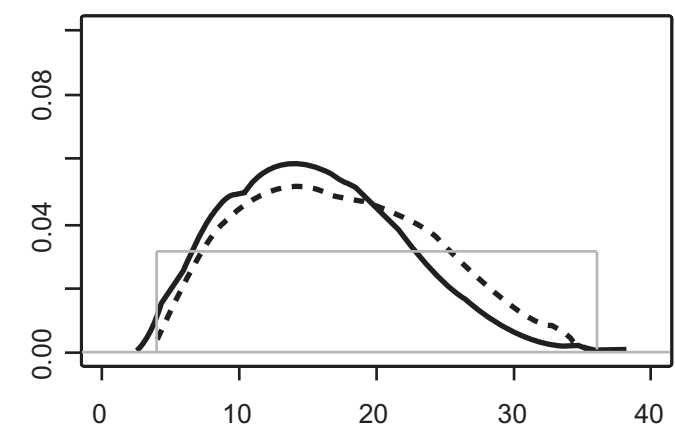

d
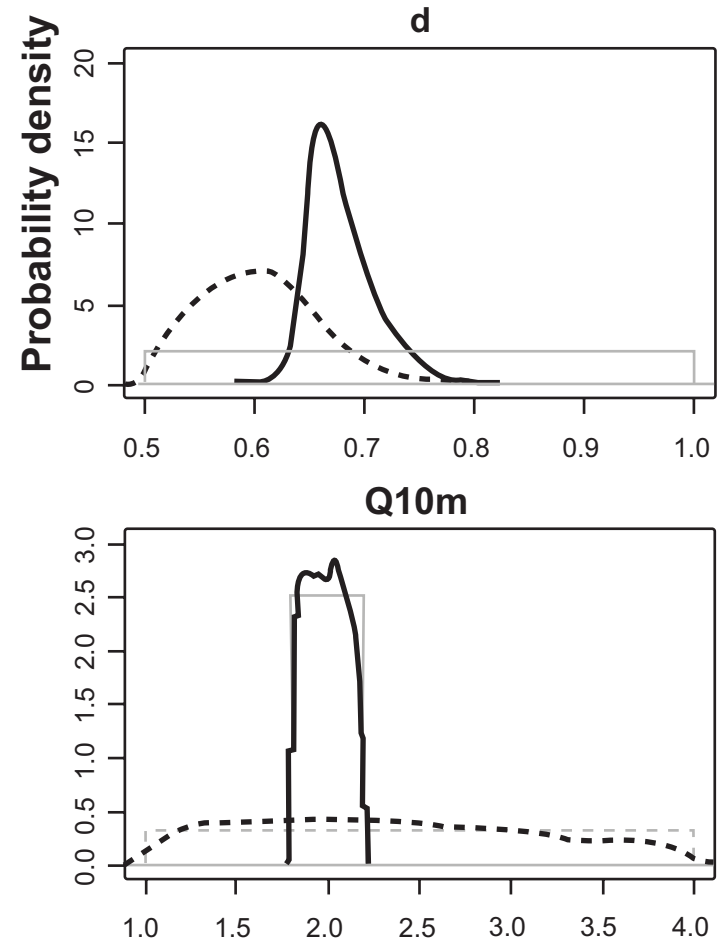

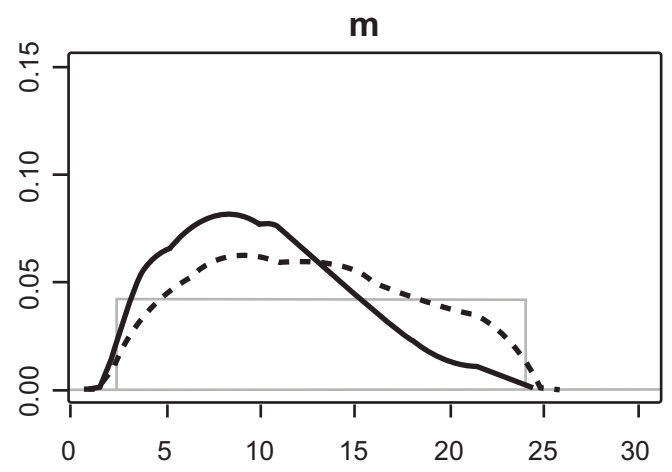

n

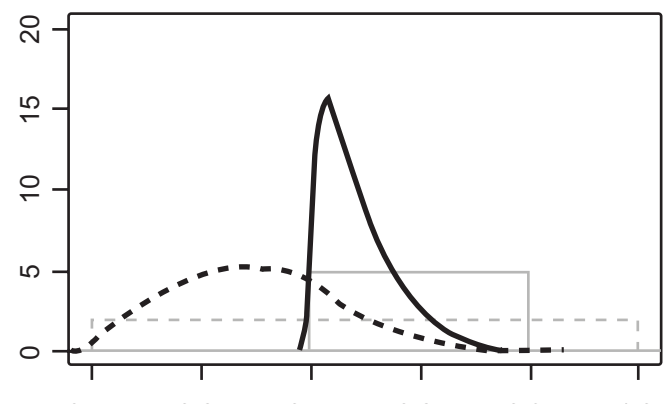

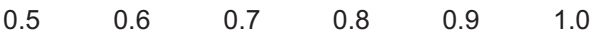

Q10C

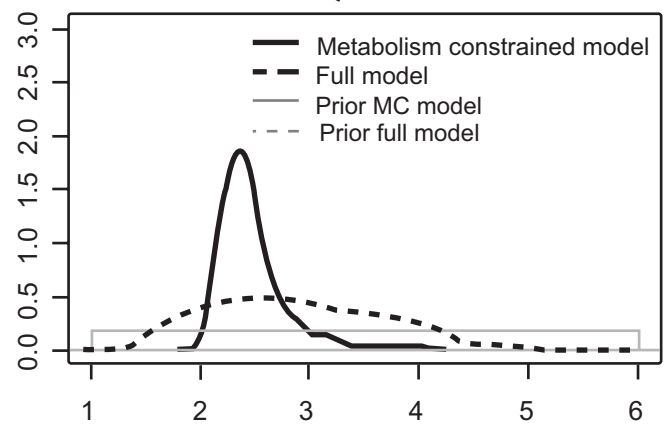

Parameter value

Fig. (4). Prior (grey) and posterior (black) probability densities for the general bioenergetics parameters from the metabolism constrained model (solid line) and full model (dashed line) fit to flathead catfish data from the Neuse River, NC.

weight occur during this time period. Fig. (2) demonstrates this growth pattern where within year capture and recaptures show high growth (non-zero slope) while captures and recaptures occurring between late summer/fall and spring show very little growth (near zero slope). Incremental growth was especially high for younger fish, generally $250-450-\mathrm{mm}$ and ages 2-5, during spring and summer (Fig. 2). Young fish were predicted to consume $600-1200 \%$ of their body mass per year.

Observed condition factor and diet data collected on flathead catfish support predicted patterns in consumption and growth from the general bioenergetics model [10]. Diet data from flathead catfish collected as part of the mark-recapture study showed flathead catfish feeding was greatest in early summer (May) and generally lower in fall (October) [15]. While this data supports the pattern predicted by the general bioenergetics model, we were unable to formally evaluate model predictions using traditional statistics. Laboratory estimates of consumption could provide an informative comparison to consumption estimates from this model; how- ever, such estimates are unavailable for adult flathead catfish. The seasonal patterns in consumption predicted by the general bioenergetics model were consistent with laboratory studies on juvenile flathead catfish. Bourret et al. [24] found that daily consumption of juvenile flathead catfish increased with higher temperatures and remained elevated at high temperatures $\left(32^{\circ} \mathrm{C}\right)$. Bourret et al. [24] also found that consumption of juvenile flathead catfish declined under $19^{\circ} \mathrm{C}$ with limited consumption below $15^{\circ} \mathrm{C}$. Our simulations predicted that the majority of flathead catfish consumption occurred from late May through August when temperatures were above $25^{\circ} \mathrm{C}$ and minimal consumption occurred between October and March when average temperatures were below $19^{\circ} \mathrm{C}$.

Wide posterior distributions on bioenergetics parameters were not unexpected for a variety of reasons. First, flathead catfish demonstrated a wide range of size at age which is likely a function of multiple growth trajectories. Each of these growth trajectories likely would have different consumptive demands and different parameter values in an en- 


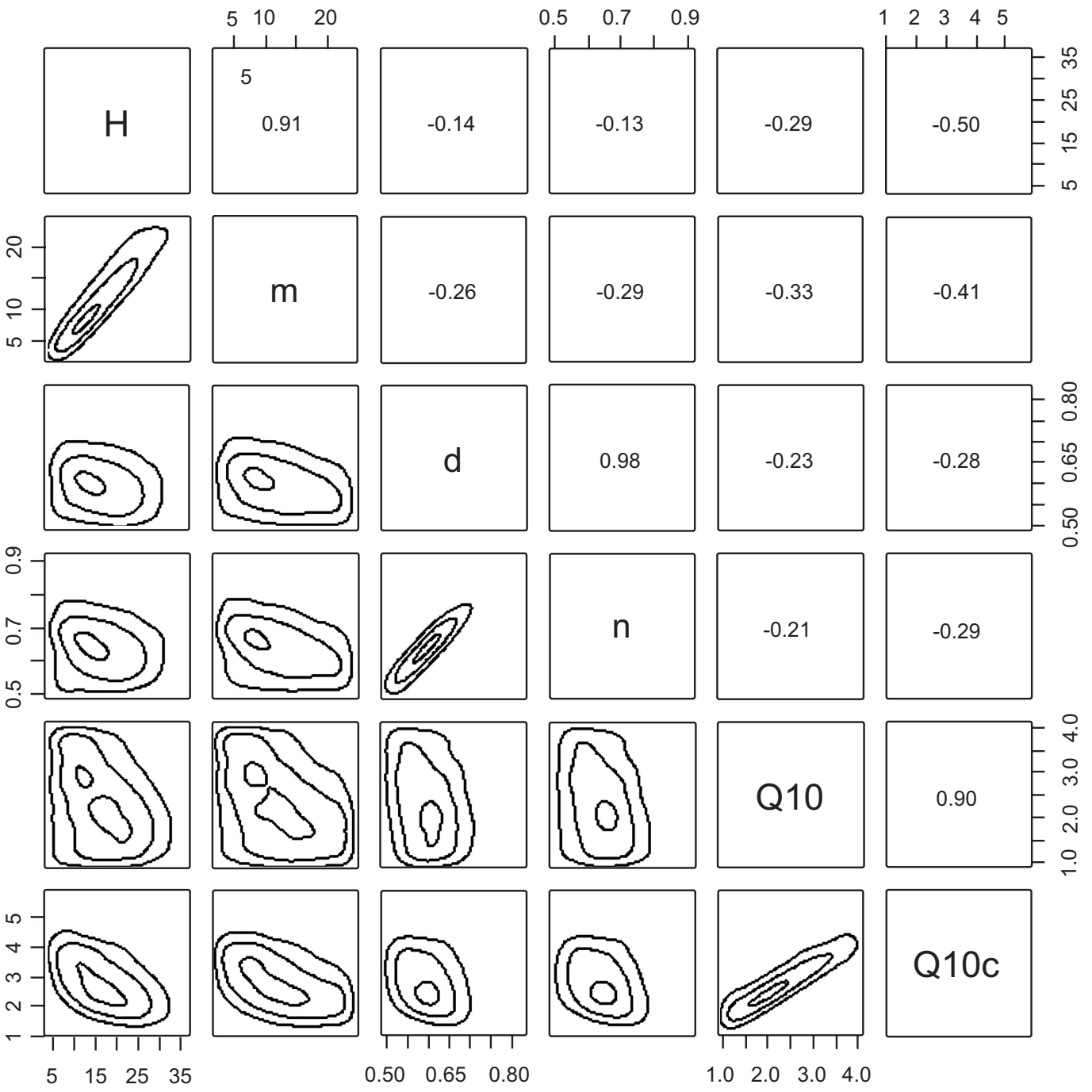

Fig. (5). Correlation matrix of parameter combinations from the full model fit for flathead catfish from the Neuse River, NC. Notice the confounding in parameter values between $\mathrm{H} / \mathrm{m}, \mathrm{d} / \mathrm{n}$ and $\mathrm{Q}_{10} / \mathrm{Q}_{10 \mathrm{c}}$ when informative priors on metabolic parameters are not used.

ergetics model framework. Our posterior distributions likely captured the range of possible values for the growth trajectories demonstrated by flathead catfish in these systems. Kwak et al. [1] found a wide range of flathead catfish growth across North America, in introduced, native, lentic, and lotic systems. Regional differences in species physiology can have an important influence on bioenergetics parameter estimates [8]. Given the large geographic distribution of this species and the high variation in temperatures and growing seasons occurring across this geographic domain it is likely that flathead catfish have wide variation in consumptive demand. This large plasticity in growth and energetics has likely served to increase the likelihood of invasion "success" of flathead catfish across North America.

Uncertainty in our parameter estimates also derived from confounding between model parameters. One artifact of this modeling approach is the high likelihood of confounding between both $H$ and $m$ and $d$ and $n$ [18]. Walters and Essington [18] suggest either fixing or placing informative priors on $n$ and $Q_{m}$ to investigate whether the $d$ and $Q_{c}$ parameters can be reasonably estimated. The use of informed priors on $n$ and $Q_{m}$ in our metabolism constrained model led to reasonable estimates and narrower posterior distributions for $d$ and $Q_{c}$. Priors on $n$ and $Q_{m}$ were derived from meta-analyses of energetics parameters across a range of species [21, 22]. Laboratory estimates of growth and consumption are unavailable for adult flathead catfish; such estimates could inform priors on bioenergetics parameters.

When priors on the metabolic parameters $n$ and $Q_{m}$ parameters were relaxed, estimates of $d$ and $Q_{c}$ had greater uncertainty and $n$ was estimated to be 0.66 . This relatively low estimate of $n$ may be related to flathead catfish activity patterns. Flathead catfish are described as sedentary, spending only a small proportion of the day active [17]. Flathead catfish habitat preferences also vary with age [25]. As flathead catfish age they tend to prefer deeper, cooler and lower velocity habitats [25]. This shift in habitat could be misinterpreted as evidence for the lower metabolism and consumption power parameters $[18,26]$. Whether the apparently low power parameters are actually due to size allometry or to size-dependent changes in habitat temperatures should not bias estimates of consumption [18]. 


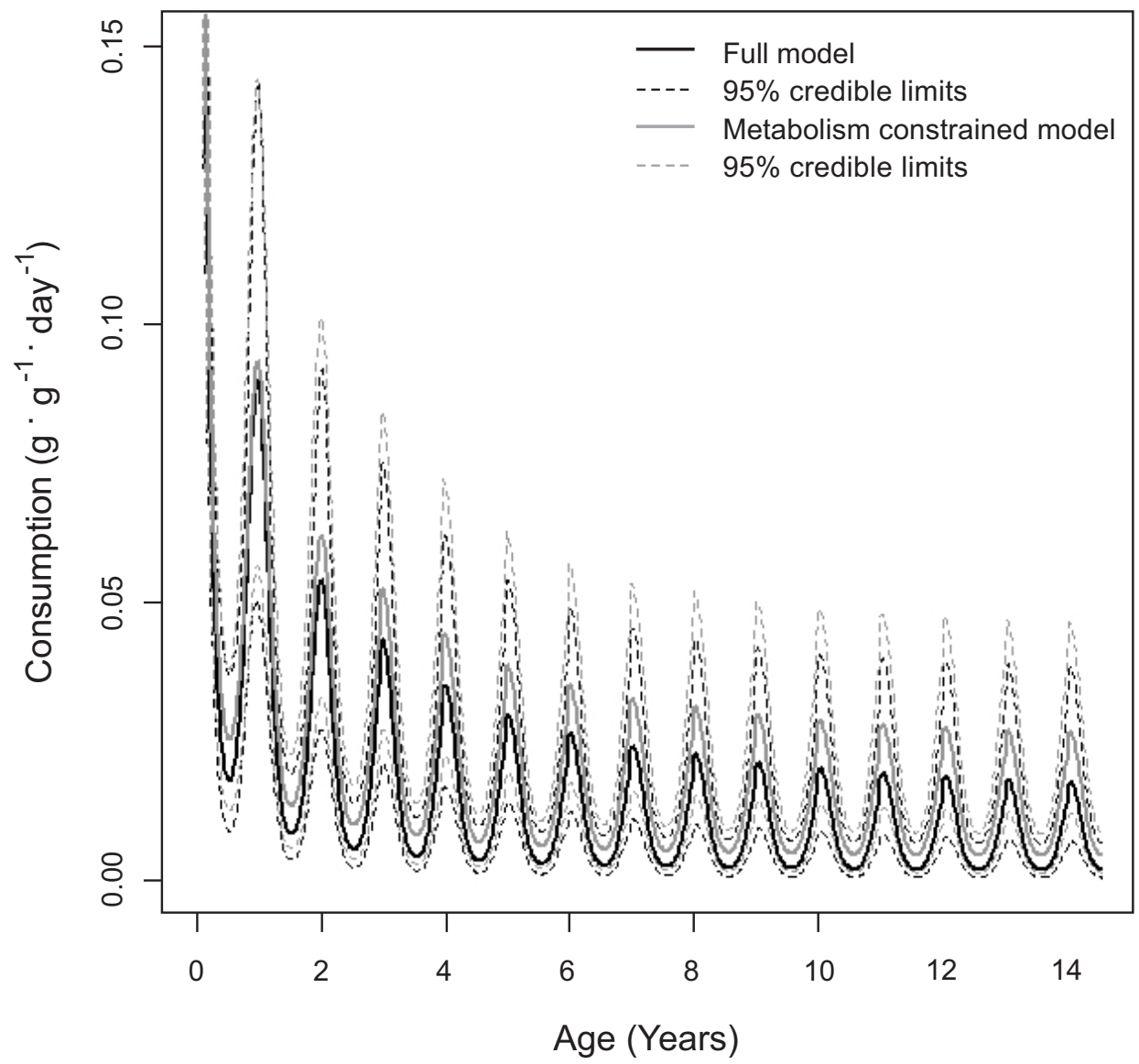

Fig. (6). Estimated daily consumption rates from the full model (black) and metabolism constrained model (grey) for flathead catfish from the Neuse River, NC. Dashed lines represent Bayesian posterior $95 \%$ credible limits.

One major limitation with available data was the inability to collect flathead catfish when water temperatures declined below about $15^{\circ} \mathrm{C}[19]$. This limited our inference to growth increment data collected during late spring-early fall (warmer weather) and from fall to spring (over winter). It appeared that limited growth (and consumption) occurred during winter periods (Fig. 2) such that the lack of observations of animal growth during winter may not cause serious bias in our estimates. Walters and Essington [18] recommend that parameter estimates be made from tagging data collected after exposure to just one strongly contrasting seasonal temperature regime. In our case, greatest inference was drawn from growth measures taken over two strongly contrasting seasonal periods, between late spring and early fall (the period of highest growth) and between late fall and early spring (the period of lowest growth). This contrast in growth was highly informative for estimates of consumption.

Flathead catfish represent a unique case study for applying the general bioenergetics model of Walters and Essington [18] due to several unique life history attributes. In addition, the general bioenergetics model relies on incremental growth in length data to inform estimates of seasonality in growth and consumption. Flathead catfish demonstrate strong allometric growth, with the ability to partition large portions of consumed energy into weight rather than length. We were able to replicate seasonal and lifetime patterns in condition factor by adjusting the proportion of energy allo- cated to growth of structural tissue ( $\mathrm{f} *_{\mathrm{s}}$ from Walters and Essington [18]) and the body weight at which allocation to skeletal growth declines to zero $\left(\mathrm{W}_{\infty}\right.$ from Walters and Essington [18]). Predicted growth patterns from our model show how catfish length asymptotes at age 10 while growth in weight continues throughout the lifetime of the fish (Fig. 3). In this case study, we used weight and body condition data to validate model predictions, however, future studies should incorporate weight information in the fitting procedure to more accurately estimate seasonality in growth and consumption.

This case study represents the first characterization of bioenergetics parameters and consumption estimates for adult flathead catfish. Use of incremental growth data in the Walters and Essington [18] general bioenergetics model informed patterns in growth and consumption. Despite a number of limitations specific to flathead catfish, the general bioenergetics model was able to adequately fit observed sizeat-age and seasonal observations of condition factor. Our results highlight the strong seasonality in consumption patterns of flathead catfish. Further validation of this modeling approach is necessary since accurate estimates of consumption are required to assess impacts of nonnative fish species on native fish communities [2]. However, the general bioenergetics model was able to provide population specific seasonal estimates of consumption rates without labor intensive diet sampling or laboratory derived estimates of growth 
and consumption relationships. The general bioenergetics model of Walters and Essington [18] offers a useful framework for combining growth, consumption, and demographic information by estimating parameters for seasonal, temperature driven variation in food consumption and metabolism rates from length-increment data associated with population monitoring programs.

\section{ACKNOWLEDGEMENTS}

We thank the North Carolina Wildlife Resources Commission for providing the funding for the original field study through Federal Aid in Sport Fish Restoration Funds (Project F-68) to the North Carolina Cooperative Fish and Wildlife Unit.

\section{REFERENCES}

[1] Kwak TJ, Pine WE III, Waters DS. Age, growth, and mortality of introduced flathead catfish in Atlantic rivers and a review of other populations. N Am J Fish Manag 2006; 26: 73-87.

[2] Johnson BM, Martinez PJ, Hawkins JA, Bestgen KR. Ranking predatory threats by nonnative fishes in the Yampa River, Colorado, via bioenergetics modeling. N Am J Fish Manag 2008; 28: 1941-53.

[3] Ruzycki JR, Beauchamp DA, Yule DL. Effects of introduced lake trout on native cutthroat trout in Yellowstone Lake. Ecol Appl 2003; 13: 23-37.

[4] Jackson DC, Irwin ER, Hubert WA, Rabeni CF, Schramm HL Jr, Coon T. In: Flathead catfish: biology and management. Catfish 2000: Proceedings of the international Ictalurid symposium. American Fisheries Society; Symposium 24, Bethesda, Maryland 1999; pp. 23-6.

[5] Pine WE III, Kwak TJ, Rice JA. Modeling management scenarios and the effects of an introduced apex predator on a coastal riverine fish community. Trans Am Fish Soc 2007; 136: 105-20.

[6] Fuller PL, Nico LG, Williams JD. Nonindigenous fishes introduced into inland waters of the United States. Special publication 27. American Fisheries Society; Bethesda, Maryland 1999.

[7] Pine WE III, Pollock KH, Hightower JE, Kwak TJ, Rice JA. A review of tagging methods for estimating fish population size and components of mortality. Fisheries 2003; 28: 10-23.

[8] Chipps SR, Wahl DH. Bioenergetics modeling in the 21st century: Reviewing new insights and revisiting old constraints. Trans Am Fish Soc 2008; 137: 298-313.

[9] Rinella MJ, Maxwell BD, Fay PK, Weaver T, Sheley RL. Control effort exacerbates invasive-species problem. Ecol Appl 2009; 19: $155-82$.
[10] Pine WE III. Population ecology of introduced flathead catfish. Doctoral Dissertation. Raleigh, North Carolina: North Carolina State University USA 2003.

[11] Bajer PG, Whitledge GW, Hayward RS. Widespread consumptiondependent systematic error in fish bioenergetics models and its implications. Can J Fish Aquat Sci 2004; 61: 2158-87.

[12] Whitledge GW, Hayward RS, Noltie DB, Wang N. Testing bioenergetics models under feeding regimes that elicit compensatory growth. Trans Am Fish Soc 1998; 127: 740-6.

[13] Lyons J, Magnuson JJ. Effects of walleye predation on the population dynamics of small littoral-zone fishes in a Northern Wisconsin lake. Trans Am Fish Soc 1987; 118: 29-39.

[14] Brewster JR. Trophic relations of introduced flathead catfish in a North Carolina piedmont river. Masters Thesis. Raleigh, North Carolina: USA North Carolina State University 2007.

[15] Pine WE III, Kwak TJ, Waters DS, Rice JA. Diet selectivity of introduced flathead catfish in coastal rivers. Trans Am Fish Soc 2005; 134: 901-9.

[16] Roell MJ, Orth DJ. Trophic basis of production of stream-dwelling smallmouth bass, rock bass, and flathead catfish in relation to invertebrate bait harvest. Trans Am Fish Soc 1993; 122: 46-62.

[17] Vokoun JC, Rabeni CF. Variation in an annual movement cycle of flathead catfish within and between two Missouri watersheds. N Am J Fish Manag 2005; 25: 563-72.

[18] Walters CJ, Essington TE. Recovery of bioenergetics parameters from information on growth. Open Fish Sci J 2009; (this issue).

[19] Kwak TJ, Pine WE III, Waters DS, Rice JA, Hightower JE, Noble RL. Population dynamics and ecology of introduced flathead catfish: phase 1. North Carolina Wildlife Resources Commission, Federal Aid in Sport Fish Restoration, Project F-68, Study 1, Final Report, Raleigh, NC 2004.

[20] Paloheimo JE, Dickie LM. Food and growth of fishes I. A growth curve derived from experimental data. J Fish Res Board Can 1965; 22: $521-42$.

[21] Essington TE, Kitchell JF, Walters CJ. The von Bertalanffy growth function, bioenergetics, and the consumption rates of fish. Can J Fish Aquat Sci 2001; 58: 2129-38.

[22] Clark A, Johnston NM. Scaling of metabolic rate with body mass and temperature in teleost fish. J Anim Ecol 1999; 68: 893-905.

[23] Gelman A, Carlin JB, Stern HS, Rubin DB. Bayesian Data Analysis. New York: Chapman and Hall 1995.

[24] Bourret SL, Tingley RW III, Kanno Y, Vokoun JC. Maximum daily consumption and specific daily metabolic demand of juvenile flathead catfish (Pylodictis olivaris). J Fresh Ecol 2008; 23: 413-9.

[25] Minckley ML, Deacon JE. Biology of the flathead catfish in Kansas. Trans Am Fish Soc 1959; 88: 344-55

[26] Coggins LG, Pine WE III. Development of a temperaturedependent growth model for the endangered humpback chub using capture-recapture data. Open Fish Sci J 2009; (this issue).

(C) Tetzlaff et al.; Licensee Bentham Open.

This is an open access article licensed under the terms of the Creative Commons Attribution Non-Commercial License (http://creativecommons.org/licenses/by-nc/3.0/) which permits unrestricted, non-commercial use, distribution and reproduction in any medium, provided the work is properly cited. 